First Peoples Child \& Family Review

A Journal on Innovation and Best Practices in Aboriginal Child Welfare Administration,

Research, Policy \& Practice

\title{
Promising practice for maintaining identities in First Nation adoption
}

\section{Jeannine Carriere}

Volume 3, Number 1, 2007

URI: https://id.erudit.org/iderudit/1069526ar

DOI: https://doi.org/10.7202/1069526ar

See table of contents

Publisher(s)

First Nations Child and Family Caring Society of Canada

ISSN

1708-489X (print)

2293-6610 (digital)

Explore this journal

Cite this article

Carriere, J. (2007). Promising practice for maintaining identities in First Nation adoption. First Peoples Child \& Family Review, 3(1), 46-64.

https://doi.org/10.7202/1069526ar

\section{Article abstract}

The purpose of this article is to explore the importance of identity in First Nation adoption. It is adapted from a PhD study completed by the author in 2005. The objectives of this study were: (1) describe how connectedness relates to health for First Nation adoptees, and (2) explore legislative, policy and program implications in the adoption of First Nation children. The findings suggest that, for First Nation adoptees, there is a causal relationship between connection to birth family, community and ancestral knowledge, adoption and health. The major finding is that loss of identity may contribute to impaired physical, spiritual, mental and emotional health for First Nation adoptees. This article provides suggestions on how identity can be preserved in First Nation adoption through programs, policies and practice.
This document is protected by copyright law. Use of the services of Érudit (including reproduction) is subject to its terms and conditions, which can be viewed online.

https://apropos.erudit.org/en/users/policy-on-use/ 
First Peoples Child \& Family Re

A Journal on Innovation and Best Practices in Aboriginal Child Welfare Administration, Research, Policy \& Practice

Volume 3, Number 1, 2007, pp. 46- 64

\section{Promising practice for maintaining identities in First Nation adoption}

Jeannine Carriere

\section{Introduction}

This article describes a journey of First Nation adoption through the eyes of First Nation adoptees. While some historical background is necessary to describe the context, this will be kept brief as the intent is to honor the voices of those who know, those who have personal testimonies to assist in the deconstruction identity as it relates to First Nation adoption. The article has been adapted from my PhD dissertation, Connectedness and Health for First Nation Adoptees. This exploration was based on personal and professional experience in the area of adoption.

As an Indigenous scholar, I wish to present my connection to this research. I am a Metis woman, adopted at birth in the Red River area of Manitoba. I was reconnected to my original family at the age of 12 when I met one of my sisters for the first time and life, since then, was never the same. Throughout my life I have met a large extended family and know through our genealogy that I am connected to the strong and courageous Metis history of Manitoba. This gives me great pride. In my life I have chosen western education as a means to survive and to get some important messages out to others through my social work practice about our ways

\section{Abstract}

The purpose of this article is to explore the importance of identity in First Nation adoption. It is adapted from a $\mathrm{PhD}$ study completed by the author in 2005. The objectives of this study were: (1) describe how connectedness relates to health for First Nation adoptees, and (2) explore legislative, policy and program implications in the adoption of First Nation children. The findings suggest that, for First Nation adoptees, there is a causal relationship between connection to birth family, community and ancestral knowledge, adoption and health. The major finding is that loss of identity may contribute to impaired physical, spiritual, mental and emotional health for First Nation adoptees. This article provides suggestions on how identity can be preserved in First Nation adoption through programs, policies and practice.

of knowing and being. This is which is why I enjoy teaching at the University of Victoria in the Indigenous Social Work program. I also believe it is important to use Indigenous methodology as much as possible and will describe some of my research process within the limitations of this article. The topic of adoption 
being near to my heart and soul became the topic for my dissertation and it continues to be a driving force in my scholarly work and community affiliations.

When selecting my research topic, I specifically chose First Nation adoption as I began this work in Alberta, where there is a Policy Directive for First Nation Adoption, which in my opinion has not served First Nation children particularly well. Since I was involved with the Ministry of Children's Services when this policy was implemented, I used it to reflect upon throughout the study as the rationale and hope the findings will also prove useful for other Indigenous peoples throughout Canada, including my own Metis community.

As history always sets the context, the article begins with a brief overview of historical background for First Nation adoption and moves on to the issue of identity. The methodology for the study is described briefly, and the participants and talking circle are introduced. The article concludes with key findings and recommendations for practice, programs and approaches which will honor and preserve identity in First Nation adoption.

\section{Background}

Although some Aboriginal scholars have examined the impact of adoption and First Nation children, Locust (2000) finds that "there is a lack of sufficient research dedicated specifically to the investigation of this issue" (p.11). Much of the literature leads a reader through an often painful journey that poignantly reveals that adoption is not a positive experience for many First Nation people (Anderson, 2000; Fournier \& Crey, 1997; Samson Flood, 1997; Spears, 2003). This difficult journey is echoed in Crey's (1997) reference to social workers as "wolves in sheep's clothing." As well, Flowers on My Grave (1997) is the story of Lester Desjarlais, a Dakota Objibwe boy from Manitoba, who committed suicide after experiencing extreme abuse. In this book, one of the Elders from his community, Maggie Blacksmith, tells of the days when private adoption agencies would receive funds between $\$ 5,000$ to $\$ 10,000$ for each child:

Big shiny cars would come onto the reserve, followed by the social worker's car. When they left, there'd be a little Indian child sitting in the back of the American car, bawling their eyes out. The social worker always had a piece of paper saying it was legal. We know the social worker was paid but we'd have known right away if any parents got money, because we lived so close together and we were all so poor, money would have been very conspicuous. If parents tried to keep their kids, the social worker would call the Mounties. (Teichrob, 1997, p.41).

Samson Flood (1995) describes the impact of adoption on Lost Bird, a Sioux child who was adopted by a general in the American army after retrieving her from underneath the body of her dead mother at Wounded Knee. Eventually, Lost Bird, herself, died a tragic death after years of appearing "tormented" with mental health problems. Samson Flood writes "the cost of being taken from the Lakota was more than the loss of her language, her music, her food, her kinship; it was the loss of her identity as a human being" (p.210). Anderson (2000) writes about being confused as a result of growing up away from her First Nation relatives and compares the experience to what she refers to as the adoption syndrome experienced by First Nation children who are emotionally, physically and spiritually driven to find themselves. Spears (2003) describes her troubled experiences in 
meeting her birth family and community while searching for her identity.

Researchers have suggested that alienation from this knowledge may be a causal factor for damaged health in First Nation adoptees. Locust (2000) observes that American Indian adoptees experience an adoption syndrome that she describes as the Split Feather Syndrome. In her study with 20 American Indian adoptees, she found that "the cluster of long-term psychological liabilities exhibited by American Indian adults who experienced non-Indian placements as children may be recognized as a syndrome, or set of symptoms" ( p.11).

Adoption breakdown or dissolution is described as the rejection by adoptees of adoptive parents and adoptive identity (Child Welfare League of America, 2000). Since there is no formal mechanism in Canada to follow up with any adoptee once the adoption order is granted in court, there is no official record of the number of adoption dissolutions with First Nation adoptees. For example, if a birth mother relinquishes her child to a private adoption agency or does not disclose the identity of the father, this child will not be recognized on Indian and Northern Affairs Canada's (INAC) A-List, which is an official record of First Nation adoptees in Canada (Bennett, 2002, p.23).

First Nation child and family services agency staff across the country can provide examples of testimonials from adoptees who have shared their stories with them. In Manitoba, adoption dissolution had been occurring at an uncomfortably high rate, leading to the development of the Manitoba First Nation Repatriation Program in 1994. This agency continues to exist today to serve as an advocate for First Nation adoptees who are searching for their birth family and community. Over the years, thousands of adoptees have come through their doors; however, to date INAC has refused to fund this service (Fournier and Crey, 1998, p.91). In fact, there are a limited number of government-funded programs in Canada that help Aboriginal adoptees find their birth families and communities which indicates a deplorable gap in service funding.

Lazarus's (1997) research draws comparisons between American and Canadian adoption systems, particularly as the systems pertain to the adoption of tribal children. Lazarus (1997) reports that adoption reformers argue that Canadian adoption laws should be amended to consider a child's culture in adoption cases. One of the biggest challenges with adoption and child welfare for First Nations in Canada is that the judicial standards are based on the best interest of the child, which often conflicts with the First Nation view that a child is a tribal member of an extended family. Lazarus explains "In Canada, as in the U.S., the problem is partly attributable to the application of culturally biased values in evaluating the ability of First Nation families to take care of their children, exacerbated by the ambiguity of the law at this time" (1997, p.266). Some examples of these cultural biases include standards for adoptive homes (e.g., space), financial status, and past child welfare or legal involvement. For instance, housing shortages on reserve sometimes necessitate that three generations live in one home (Royal Commission Report 1996). However, this practice may not be viewed positively by mainstream standards. In Alberta, the Adoption Regulations ensure that home assessment requirements include the exploration of space, financial capacity and others in the home. Adoptive homes are defined as having 'parents' without emphasis on extended families 
or kinship structures. In a section entitled "Family Dynamics" there is no mention of grandparents or extended family. The autonomy of family members is explored (Alberta Regulation 187/2004. Adoption Regulations). These regulations imply a western view of family and child caring practices.

Lazarus views the National Indian Child Welfare Act in the United States as a tool that assists tribes to prevent the adoption of Native American children by non-Indian parents, giving increased jurisdiction in matters of child welfare services to Indian families (1997, p.270). The National Indian Child Welfare Association (NICWA) in the United States, which has been prominent in advancing research and practice for Aboriginal child welfare services in Canada, was instrumental in lobbying for the proclamation of the National Indian Child Welfare Act in the United States. NICWA has held a number of annual conferences addressing a range of topics related to practice with Aboriginal children and families and continues to advocate for the rights of Native American children and adoption. For example, the Multi-Ethnic Placement Act (P.L. 103-82) was passed in 1994 "in response to a belief that policies which gave consideration to race, color or national origin in making foster care and adoptive placement decisions often created a barrier to achieving permanency for children of color" (NICWA, 1999, p.1).

A major limitation of the Indian Child Welfare Act (ICWA) is that it does not apply to children who are not registered with the Bureau of Indian Affairs. This also means that Indigenous children from Canada such as Metis, Inuit or First Nation children who are not from recognized tribes and adopted in the U.S. are not protected through this legislation. The only exception is the State of Washington where steps have been taken to broaden the scope of ICWA. Without protection under ICWA, Indigenous children are not given any cultural considerations under the Multi-Ethnic Placement Act (1994).

Unfortunately, a guarantee for an Indigenous child's cultural rights is not generally applied in Canada either. For First Nation children, Canadian provinces continue to administer adoption programs with little or no consideration to the inherent rights of a First Nation person. Canadian policy places the issue of adoption and First Nation children within a context of cross-cultural adoption, failing to recognize the contradictions in this practice. The issue is not about race, colour or national origin; it is about the preservation of First Nation self-determination within a continuing colonial context. The federal funding formulas for on reserve service delivery do not provide any funding for the range of adoption services and as a result, there are very few culturally based adoption programs.

The next section provides an overview of key literature on identity and First Nation adoption, leading into the key findings of this study.

\section{Identity and First Nation Adoption}

The issue of identity has been discussed as a prevalent issue in cross cultural and First Nation adoption literature and is a theme in this study. It is important to understand the importance of tribal identity in order to recognize the impact of separation or disconnection from tribal knowledge and connection for First Nation children. Cajete (2000) explains that:

Relationship is the cornerstone of tribal community, and the nature and expression of community is the foundation of tribal 
Promising practice for maintaining identities in First Nation adoption

identity. Through community, Indian people come to understand their "personhood" and their connection to the communal soul of their people (p.86).

In a recent article published in Adoption and Ethics (2000), the Child Welfare League of America (CWLA) attempts to analyze the National Indian Child Welfare Act as it relates to race, culture and identity. The CWLA states that, "although race and culture have played important roles in the adoption of African American, Latino and other children of colour, culture - by virtue of both history and legislative action, it has played a unique role in the adoption of American Indian children in the U.S." (2000, p.57). The National Indian Child Welfare Act (NICWA) recognizes the importance of Indian children's cultural heritage and was enacted to "halt the systematic separation of Indian children from their families and cultural communities" (CWLA, 2000, p.57).

The CWLA also discusses the work of some prominent American researchers in this area. For example, Fanshel (as cited in CWLA, 2000) reports that outcomes for Indian children adopted by Caucasian families are related to problem areas of personality rather than structural or systemic issues. In other words, the dynamics of poor matching resulting in strained relationships and personality conflicts are more crucial to the wellbeing of children than any other systemic malfunction. Fulcher (2002) asserts that child welfare authorities with a duty of caring for the health and well-being of children need to produce services that guarantee cultural safety, which Fulcher defines as "the acknowledgement of and attendance to a child's needs and cultural frame of reference" (p.689).

Yeo (2003) states that "Spirituality is the cornerstone of identity" for Aboriginal children (p.294). Practitioners who have advocated for adult First Nation adoptees concur. In their study, An Evaluation of the Southern Manitoba First Nation Repatriation Program (Bennett, 2001), researchers interviewed First Nation adoptees who have been repatriated to their family and community. A notable response among a majority of interviewees was that they felt that it was important to know about their ancestral background (2001, p.31). One of the most common reasons that First Nation adoptees wanted to be reconnected to family and community was to gain "official recognition of who they are, as an Indian person” (2001, p.14) $)^{1}$.

Anderson (2000) illustrates her search for her identity as an Aboriginal woman who grew up away from her family and community. She describes how she struggled with increased knowledge about Aboriginal people, especially while taking university classes and examining issues from the voice and writings of others. Anderson proposes a theory of identity formation for Aboriginal people that includes four steps: (1) resisting definitions of being or rejecting negative stereotypes, (2) reclaiming Aboriginal tradition, (3) constructing a positive identity by translating tradition into the contemporary context, and (4) acting (e.g., using one's voice) on a new positive identity (p.229).

Kral (2003) discusses identity in his study on meanings of well-being in Inuit communities. He notes that Aboriginal people have collective selves and that "collective selves see group membership as central to their identity whereas individualistic selves are more autonomous from any particular group and may value individualism quite highly" (2003, p.8). This collective worldview values kinship as the foundation of social life. Kral proposes that 
in Inuit communities, kinship is viewed as an important area of traditional knowledge. The importance of family and kinship was the most prominent theme across Kral's 90 interviews with Inuit people who explained that this connection was a determinant of well-being and prevention.

Grotevant, Dunbar, Kohler and Esau (2000) challenge the argument that adoption policies related to confidentiality enable a severing of ties with birth families in order to promote attachment to adoptive parents (p.379). Grotevant et al., in support of other researchers, refute this notion and, in particular, the pretence that adoptive parents can replace biological parents by erasing all existing pertinent information about the biological parents. Grotevant et al. conclude that changing policy can challenge this assumption and that an openness in adoption likely will have an impact on a variety of complex adoption issues, including identity formation, which they describe as "central to the emerging understanding of adoptive identity" (2000, p.385). Grotevant et al. also identify a need for further research in adoption and, in particular, investigation into the diverse social contexts that can influence identity formation.

In summary, the complexity of identity as it relates to adoption and First Nation children is enhanced by various political and legal dynamics. For example, what would be the impact on adoption policy and practice for First Nation children if culture and identity were viewed as protective factors for resilience? Indigenous scholars have proposed that individual identity is inseparable from the collective identity of Aboriginal people (Anderson, 2000; Bennett, 2001; Brendtro, Brokenleg ,Bockern, 1990; Kral, 2003). Some of the adoptees in this study spoke at length about identity confusion and the need to reconstruct themselves from a continual flow of new information as they met their extended family members.

\section{Methodology}

To understand the experience of First Nation adoptees in terms of connectedness and health, participants involved in this study were asked to reflect on meanings attached to the adoption experience. The strength of this type of qualitative approach is described as emancipatory social research (Lather, 1991) in which both the researcher and participants become changed. Olesen (1994) describes it as "giving voice to the voiceless" (p.169). One of the strengths of qualitative research is the focus on how humans make sense of their surroundings and interpret phenomena to provide the context, and a complex and holistic picture of an event or situation (Creswell, 1998; Denzin \& Lincoln, 1994; Patton, 1990).

The entire research process was reviewed by and received guidance from a First Nation Community Advisory Committee, which represents the five First Nations of the Yellowhead Tribal Council, comprised of Elders and staff from the Yellowhead Tribal Services Agency's Open-Customary Adoption Program. Its role was to provide suggestions to me regarding the research process, including community protocols and political or cultural matters that informed this study. The Committee recommended potential adoptees and key informants for inclusion in this study and provided feedback on research questions. This feedback was considered carefully in developing the interview guide. The Committee also made recommendations regarding the dissemination of research results. 
Throughout this study, the Community Advisory Committee provided important information about cultural boundaries which are identified as important in the literature (Rubin \& Rubin, 1995). Furthermore, the Committee expressed caution about how I should present myself as a researcher to the interview participants, the adoptees. In other words, they encouraged me to be honest and 'speak from the heart' led by a clear mind (NAHO, 2003). This involved a process in which I provided my cultural credentials as to who I am in the community as a Métis woman and who my relatives are. It also required me to be very clear in describing the potential benefits to the First Nation community. It is with thanks to the Community Advisory Committee that I was able to develop a research protocol for the study and a cultural safety protocol for interviewing adoptees.

Talking circles were used to gather information from key informants. Key informants included Elders, staff, adoptive parents and board members for the Yellowhead Tribal Services Agency Open Customary Adoption Program. This information, in turn, enhanced the adoptee interviews. The use of talking circles, as an indigenous method of knowledge building, replaced the conventional use of western focus groups.

\section{Cultural Process}

Several cultural practices were observed for receiving permission and spiritual grounding for this study. As explained earlier, I received a vision of this work at the onset of my $\mathrm{PhD}$ program through an experience in a sweat lodge. This experience was influential in ensuring that the cultural process was honoured and that the blessings of the Elders were received as crucial elements of this work, which has been a profound spiritual experience for me. These elements are part of the foundation or epistemology of indigenous thought and knowledge, demonstrating the recognition that spiritual forces, described as energy, guide our daily lives. This energy influences the environment in which we live and interact with other living beings. Indigenous science also informs us that we are not separate from our ancestors and that we can connect with them through dreams, prayers, ceremony and prayer. For this study, I felt it was essential to engage in a process that honoured these ways of knowing and being since I felt that the ancestors have played a critical role in which I am and ultimately, in how this work was conducted.

The data gathering process for this study has been impacted significantly by this indigenous paradigm. Sinclair (2004) stresses, "from an indigenous worldview the offering of tobacco and engaging in ceremony and prayer is actually the beginning of a research project" (p.124). Not all indigenous people use tobacco in their spiritual work. However, the importance of spiritual processes appears to be a common approach to healing work. Cajete (2000) states that indigenous people believe that the real test of living is to establish harmonious relationships with nature and this is the "source of one's essential spiritual being” (p.179). For this study, I received strength, wisdom and vision through reflection, prayer and ceremony, and thereby, was able to create a positive energy for the participants in the study. And, at the beginning of this process, one of the first opportunities for me to honour this way of being was with Elder Bluestone Yellowface.

Elder Bluestone is Saulteaux and is from the O'Chiese First Nation in central Alberta. While her age is unknown to me, what I have recognized and experienced is her wisdom, knowledge and kindness. She has 
been instrumental in the development of all Yellowhead Tribal Services Agency programs since the first priority in her work is children. Elder Bluestone has raised many children through customary adoption in her own tribal customs as well as through the Alberta child welfare system. At the beginning of the study, Elder Bluestone advised several of us that long ago children who had no parents were called Aski-awass or children of the earth because it was thought that Mother Earth would look after them. Her words are exceptionally inspirational, affirming that spiritual forces or energy guide our daily lives. If we believe that the earth is our relative and that we have a mutual responsibility to each other, to the earth and to ourselves, we have a different view of processes, such as child-rearing and caregiving. In other words, these responsibilities are not sanctioned or administered through court work and the intrusion of foreign law. They are a natural part of life or living in balance with natural laws that encourage us to walk in balance with the universe and care for each other as a natural part of life.

It has taken me some time to understand some of these concepts since I am one of those children of the earth who, thankfully, was looked after by loving adoptive parents. As my life has evolved, I have come to appreciate the ancestral knowledge that is part of my make-up and that reminds me that in my work and other areas of my life these beliefs and processes must be respected. For this reason, sitting in ceremony throughout this study was essential.

\section{The Participants}

Eighteen First Nation adoptees participated in this study. Their background varies by gender and age. Four of the 18 adoptees are male while the remainder are female. Their ages range from early 20 s to mid-40s. Sixteen adoptees were adopted at age 5 or younger while two were adopted at age 10. Seventeen had their first original family contact during their adolescence or in their twenties while one adoptee met her birth family at age 11 . Three adoptees are university students and two are homemakers. Thirteen are employed in professional or paraprofessional occupations. Their geographical locations include the provinces of British Columbia, Alberta, Manitoba and Ontario.

Within the adoptive family systems, 15 adoptees were placed with Caucasian families and three were placed with First Nation adoptive parents. Some of the prevalent issues in the adoptive families are that for 12 of the 18 adoptees, their adoptive families fostered or adopted other children. Six adoptive parents supported the reunion experience. Individually, seven of the 18 adoptive fathers had alcohol problems. Three of four male adoptees reported that they had conflict with their fathers while nine out of 18 female adoptees reported conflict with their mothers.

Within original family descriptions, sixteen adoptees described drug and alcohol problems with one or both birth parents. Thirteen reported that they had met their biological mothers and ten have not met their birth father, including four who described their biological father as unknown. Most adoptees have good rapport with at least one sibling, but there was limited mention of extended family, such as grandparents, aunts or uncles. Two adoptees mentioned aunts or uncles. Ten of the adoptees described their birth family as disappointing, unhealthy or dysfunctional. Seven reported one of their birth parents as deceased.

The in-depth interviews with each of the eighteen adoptees were enhanced by two talking circles 
Promising practice for maintaining identities in First Nation adoption

composed of Elders, staff, board members and adoptive parents for the Yellowhead Tribal Services Agency (YTSA) Open Customary Adoption program in Alberta. I wish to acknowledge their valuable input into this work but for the purposes of this article will focus on findings from participant interviews at this time as it relates to identity and adoption. It is important to note that each participant was asked to choose a name to represent themselves in this study in order to protect their anonymity and that of their families.

\section{What Adoptees in this Study Said About Loss and Identity}

Loss became the core category in this study. Loss was expressed to some degree by each of the adoptees and often was manifested in their health, which for this study has been organized into physical, emotional, mental and spiritual health sub-categories.

The most challenging task in defining a core category for this study was to determine if identity superseded loss or if loss was an overarching category that encompassed identity as one form of loss. By using a qualitative method of constant comparison method of analysis while reading and rereading the transcripts, it became clear that loss was the overarching core category. Each adoptee experienced loss in several areas of her or his life. This loss prevailed in profound ways throughout an adoptee's life, eventually manifesting itself in emotional, physical, mental and spiritual areas. In this study, loss is described as having many characteristics.

In this study, identity was viewed by all 18 adoptees as the main loss that they experienced through adoption ${ }^{2}$. Eagle shares a personal analysis of her loss:
They just took us, shipped us off, put us somewhere else and forgot about us; that's it. I think they should be accountable for that, because - I know there were good adoptions, and a lot of kids probably had good lives, but I would say the majority of the adoptions were - and foster home placements were not so good. I hear so many stories of things that happened. I hear very few success stories. You know what I mean? I always hear adoptees saying how lost they felt and how disconnected and "Who am I? Who are my people?" Lots of emotional instabilities, like, I put down right here, there's a lot of unrest and I think -I don't know what the government was thinking, what their reason was that they felt they had the right to do this. (Eagle)

All 18 adoptees explained that their drive to seek out their birth family stemmed from questions about and a longing to know who they are, where they come from, and where they belong in this world. Molly explains:

For me, I grew up thinking that I was a nobody, like, I didn't know my identity. So, when I was a teenager, I went through an identity crisis because that's when I started realizing I WAS different. There was something different about me. (Molly)

The search for identity encouraged some to begin observing First Nation people for the first time in their life. Mama Bear states:

When I was 12, that's when I started questioning. I wanted to know more about native people. There was a Hudson Bay store, and I knew they did all their groceries. I was always going there to sit on a bench and watch them. I wanted to know things. I wanted to be a native person so badly. (Mama Bear)

Eagle, who grew up in the U.S. expressed a frustration that she couldn't find anyone to identify with: 
Actually, the schools I went to, yeah, was mostly Hispanic and white people. I always knew I was native, but I didn't know anything about that - like I never even heard the term Aboriginal until I came up here. (Eagle)

For Donna, finding out about her identity is now central to her life:

So right now, it's identity issues. It's becoming a bigger part of my life, of finding out who I am and putting all the pieces together and finding out about my culture, and I am drawn more to Aboriginal communities. (Donna)

Mona believes that if she perhaps had been placed with her same cultural group, her life might have been different:

Because if I had been adopted into an Aboriginal family...(pause)...how would you say it? I'd be the same as them I guess. (Mona)

In contrast, Christina was adopted by First Nation parents. However, she did not know about her biological family background until she began her search. Her greatest fear was that she would date someone she was related to:

Like I said, finding out that I was adopted, the only thing it did for me was confuse certain things, that's all. The other thing I was afraid of is, "Who am I related to? Who can I go out with?" You know, "Who's my relative?" (Christina)

Similar to Christina, most of the adoptees in this study asked themselves the same questions: Who am I? and Where do I come from? This explains part of the excitement in meeting people you are related to for the first time in your life.

For those adoptees who discovered people who looked like them, for the first time in their lives, the impact of the experience was overwhelming. In meeting her aunt, Rose explains:

Oh, it was just like coming home! I mean, she looks a lot like me. We have the same eyes - she's only a couple of years older than I am. We have the same quirky sense of humor. Her son would be a year older than my son. (Rose)

Similarly, Billy remarks:

It was finally a relief because I knew that I actually looked like somebody. Because maybe as a kid and teenager and as an adult, I always went, "I don't look like anybody." I mean, people would say, "You sort of look like your adopted mother and brother - but upon closer examination you see we don't...(pause)...I don't look like them. Now, I know there are people out there who I look like. (Billy)

Jane enthusiastically acknowledged how the resemblance made her feel:

I felt happy. I'd look at her, and I'd say, "That's where I got my nose from. That's where I got my hands and feet, things like that. Just to see her (birth mom) and be able to take pictures of her with the kids and stuff like that, and I thought, "That's my mom. That's where I came from." (Jane)

The search and reconnection with original family members provided a number of adoptees with a sense of belonging that they described as missing from their childhood.

Other adoptees during their childhood anxiously sought out a place to belong even if their actions potentially placed them at risk:

I barely ever came home. If I did come home it was like late at night which got me into more trouble and got me into more confrontation with my (adoptive) dad and then it was like when 
Promising practice for maintaining identities in First Nation adoption

I turned 15, I just, I just couldn't take it any longer. I just packed my bags. They asked where I was going, and I just looked at them and I said, "I don't know. I just know I don't belong here." (Marty)

Reunions however, are not always a positive experience for adoptees. Some adoptees described their birth families as dysfunctional or unhealthy, but the urge to maintain ties remains a traumatic bond that is difficult to break. This experience caused deep emotional pain for each adoptee who had witnessed this other face of reunion. Sarah describes the disappointment:

Yeah, sometimes my sister would say; "Ya, I'm going to take you on a trip. We're going to go here, and we're going to go down." And then, she'd promise me she'd come pick me up to do stuff with me and then she'd never show up. (Sarah)

Paris shares this experience with her mother:

I met my mom. I got to know people in the family and a lot of them don't talk to each other. There's always that fighting going on, which I don't understand, because I can't imagine not ever talking to my kids or my brother for any length of time. Sure, we get mad at each other, but this family, they get - you say something the wrong way, and they won't talk to you. And, my mom has pulled that off on me since I met her. I express myself, I confront, and I share my feelings and she's the type that thinks that's wrong and then I won't talk to her for two years. (Paris)

In discussing various losses, most adoptees in this study remarked on the need to preserve identity for First Nation adoptees.

Angel felt that if she could have had more cultural teachings, it might have helped in her emotional healing in finding herself:
If I could at least know about what kind of person I was, where I came from, what band and all those things - what my mother's name was and my dad's name and all those things - I needed more interaction with Aboriginal people, instead of white people giving me their idea of what Aboriginal people do. (Angel)

Other adoptees like Mama Bear expressed a similar frustration of not knowing yet feeling like they should have known:
I would have liked to learn my language and know more about my tradition. That's what I miss; my language and my tradition that I lost it, and it's hard to get back. I'll probably never get it back and my kids lost it, too. (Mama Bear)

Billy, Rose and Christina wished they had been exposed to more cultural events, such as pow-wows and other cultural traditions. Some adoptees, such as Arthur, Eagle, Molly, and Sierra, did not know what tribal background they were from, which they often found confusing or humiliating. Sierra recounts:

I never really knew until I was eighteen where I was from. I thought I was told that I was Cree, and it wasn't until I was talking with my biological dad one day and he said, 'You're not Cree. You're Ojibway. You're from (community) and that's all Ojibway land. I had heard for so many years that I was Cree because that's what I had been told by my adoptive parents and that's what they were told. So, it was a shock, it really was. So, all over the place, I had been learning Lakota tradition thinking I was Cree, but really Ojibway. (Sierra)

\section{A Summary of Recommendations}

The following summarizes the recommendations provided by the participants in this study. 


\section{Information}

1. Information on birth family should be made available to adoptees as soon as they desire it.

2. Health information from birth families is preserved for adoptees.

3. Post-Adoption registries need to be revised to (a) allow access to other birth family members, such as extended family, and (b) provide information to adoptees when they want it.

4. Pictures should be available to birth families and to adoptees.

5. First Nation adoptees need to know which tribe and First Nation they are from.

\section{Adoption Practices}

1. Adoption of First Nation children should be in First Nation or Aboriginal homes if at all possible.

2. Connection to extended family and community should not be severed through adoption.

3. If First Nation children are not placed in a First Nation home, cultural training needs to be provided to adoptive parents.

4. Cultural mentors should be provided to First Nation adoptees to assist in reconnecting to their cultural heritage.

5. Adoptive homes need to continue to be monitored by child and family services agencies somehow.

\section{Legislation}

1. The legislation on adoption of First Nation children needs to be explored further. At minimum, it needs to be open.

2. Customary adoption requires further support.

() Jeannine Carriere
3. The rights of adoptees to receive all information about their identity, extended family and community of origin need to be defined further in adoption legislation, policy and standards.

Support

1. Adoptees involved in search and reunion require support services to assist them in these processes.

2. Peer support groups for First Nation adoptees need to be established.

3. Counseling services should be made available to First Nation adoptees.

These recommendations have implications for First Nation adoption practice with policy and program implications. The analysis of adoptee recommendations lead to proposals for program, policy and practice captured as follows:

\section{Recommendations for the Development and Delivery of First Nation Adoption Programs}

\section{Open and Customary Adoption Programs across Canada}

Throughout this study, all the participants, both the adoptees and key informants, discussed the importance of openness in adoption practices. Openness could prevent the secrecy and hidden information that was discussed at length by the adoptees as one of their major barriers to their search. This secrecy and lack of information created undue stress about personal health information and not knowing possible relatives.

Furthermore, while some provinces in Canada, including Alberta, boast of having open adoption programs (Alberta Child Welfare Act, 2000; Ontario Child and Family Services Act, 2002), these programs continue to be developed and implemented under provincial legislation 
based on a non-First Nation perspective. Open adoption programs for First Nation children must be redefined based on an indigenous paradigm that is anchored in the reality of delivering child and family services both on and off reserve. A case in point is the recently publicized court hearing for five First Nation children in Saskatchewan that challenged the provincial policy on First Nation adoption. Saskatchewan's policy, similar to Alberta's Policy Directive in the Adoption of First Nation Children, prevents First Nation children from being adopted without consent from the child's First Nation. In this case, the Court of Queen's Bench judge refuted the First Nation agency's claim that it had the authority to "speak for the children" and ruled that there is no constitutional basis or Aboriginal rights related to equality, liberty and security in this matter (Province of Saskatchewan Queen's Bench Family Law Division 503, 2004, p. 28). This legal precedent marks yet another instance where the right to culture and birth family connection are highlighted in a judicial process in which an individual judge makes a decision based on what he/she perceives as the lack of evidence to support an alternative decision. I would suggest that this study may have given her additional considerations for this matter. Without doubt, this case will be appealed. The disturbing irony in this situation is that the focus is being misdirected. First Nation rights are being discredited while the same child welfare practices, such as poor matching and support, and the resulting untenable foster care drift for these children, are being ignored.

As well, customary adoption practices need to be revived in First Nation communities with adequate financial support (Alberta Children's Services, 2000; D’Aguayo, 1995; YTSA,
2001). Although customary adoption is a traditional extended family value and practice for First Nations, the reality of poverty and the shortage of resources in extended family networks should not be insurmountable barriers. Indian and Northern Affairs Canada (INAC) must stop patronizing First Nation Child and Family Services by proposing that they develop adoption programs on menial budget allocations.

\section{Financial Support for First Nation Adoption Programs}

The recommendation for First Nation adoptive homes also requires adequate financial support (Rechner, 2001; Trocme, Knoke \& Blackstock, 2004) for First Nation adoption programs. INAC's financial allocations for adoption must be reviewed by a Standing Committee on First Nation adoption comprised of First Nation Child and Family Services National Directors and representatives from the Assembly of First Nations (AFN). The Standing Committee could make recommendations based on research and statistics regarding the social costs of adoption breakdown compared to the benefits of financial support in the area of adoption to First Nation agencies. As well, child and family services on and off reserve should include adoption services instead of being limited to child protection services.

\section{Adoption Registries}

Some of the participants in this study discussed problems and experiences with adoption registries. Adoption registries should be revised to address the enormous demand for First Nation "friendly" adoption registries. This type of registry would clearly identify a child's First Nation ancestry and be expanded to include extended family members. Also, registry staff should receive training in working with First 
Nation communities to provide the type of counsel required for First Nation adoptees pursuing a search.

\subsection{Veto}

Veto issues related to registries need to be revised based on consultation with First Nation communities. The issue of treaty and collective rights need to be considered in developing policies around veto issues.

\section{Adoption Social Work Practice}

Adoption workers need to begin adoption work with a consultation session with the child's First Nation community through delegated child protection workers or others who represent the interests of the leadership and community. Mirwaldt (2004) discusses the high number of Aboriginal children needing permanent care; "meaningful case consultation with the Aboriginal community is stressed as being fundamental to good permanency planning practice" (p. 18).

\subsection{Relinquishment Counseling}

Participants recommended the need for counseling for their birth family members. This would include relinquishment counseling for both birth parents to ensure that adoption is the best choice. It also includes some encouragement to birth parents to provide as much information about each of the birth parent's family and health histories. Any information about extended family and community of origin also should be collected at this time. For birth parents, there also is a need to ensure that relinquishment is truly the option of choice. A study focusing on young mothers involved with the $\mathrm{BC}$ child welfare system reports that, "In $\mathrm{BC}$ today, as has been true throughout the last century, those who are most likely to lose their children are poor, young, Aboriginal and come from families that have historical involvement with child welfare" (Rutman, Strega, Callahan \& Dominelli, 2001, p. 6). Relinquishment counseling requires further study, but it is relevant for adoptees and birth parents due to life-long implications for those involved.

\subsection{Photos}

A number of participants mentioned that photos of birth families are precious. Photos of birth parents, siblings and/or extended family members should be saved for the adoptee. Photos of the adoptee saved in a resource, such as a Life Book, would be a valuable source of information and comfort to facilitate a future reunion for both adoptees and birth families. Adoptees in this study described the importance of 'looking like someone' for example. Life books can take the form of scrapbooks or collections of photos and history which can enhance connectedness for adopted children (Fulcher, 2002; Society of Special Needs Adoptive Parents, 2003).

\subsection{Information on Birth Fathers}

As discussed in this study by some participants, knowledge and information about birth fathers is critical for adoptees because it essentially is the other half of the parental equation (Coles, 2004; Menard, 1997). It is imperative that birth mothers provide this information to the best of their knowledge and that it becomes part of the relinquishing file documentation. This information can be a legislated requirement, but will require further consideration in light of privacy legislation.

\subsection{Registration for Indian Status}

Registration for Indian Status requires birth parents and adoptive parents to 
ensure that children, who are eligible, are registered as Status Indians at the Indian and Northern Affairs Canada registry. In order to preserve a child's treaty rights as a First Nation person, adoption workers need to be diligent about identifying First Nation children who are placed for adoption. Some participants in this study described some difficulties in being registered.

\subsection{Training for Adoptive Parents and Adoption Workers}

Some participants in the study suggested that training might have assisted their adoptive parents to understand their background and culture. Training for adoptive parents and adoption workers should involve the development of a module that explains the rights of a First Nation child, shares historical information, and identifies resources where additional information can be obtained (Society of Special Needs Adoptive Parents, 2003). As well, a First Nation person should deliver this module. Additionally, research and training regarding culturally competent adoptive care of First Nation children is of great importance. Some of the adoptees in this study suggested that this training be included as part of the services provided to adoptive parents. In particular, nonFirst Nation adoptive families need information about the child's home community, language and history. While sharing this information may be difficult in closed adoptions because of stringent confidentiality rules, adoption legislation and policies must address this issue. Adoption workers also need to be trained to be culturally competent in working with Aboriginal children and families. For example, some of the adoptees in this study were not sure which tribal background they were from so they assumed a tribal ancestry which was inaccurate. They suggested that training for adoptive parents might have alleviated this.

\section{Cultural Plans}

Cultural plans should be mandatory for First Nation children. These plans contain provisions to maintain contact with the child's First Nation community and culture and are signed by both the adoptive parents and representatives of the child's First Nation community. This practice should be mandatory in the adoption of all First Nation children (Fulcher, 2002).

\section{Repatriation Services}

First Nation agencies need to be supported in repatriation services for adult adoptees. This support should be provided through Indian and Northern Affairs Canada in their funding for child and family services. This is a critical service that should be free for adoptees who wish to be reconnected to their First Nation community.

\section{Counseling and Peer Support for Adoptees}

If needed, First Nation adoptees should be provided with therapeutic supports and interventions to assist with loss issues connected to adoption. These interventions can range from Western approaches, such as individual counseling and peer support to traditional indigenous methods, such as ceremony and meeting with Elders. There are resource implications for any of the approaches, and resources should be provided as part of the repatriation services for First Nations on and off reserve.

\section{First Nation Community Mentors}

First Nation Child and Family Services Agencies (FNCFA) need to establish a resource list of community mentors for adoptees who 
return to their home community. The names of these individuals can be recorded at the Band Office of the child's First Nation. Mentors could provide family history and other required information to adoptees or assist in making linkages with extended family. Training for mentors should be funded and provided by FNCFAs through resources from repatriation budget allocations.

\section{Health Information}

Adoption files should contain family health history for both birth parents as a mandatory requirement and be provided to the adoptive parents during the adoption process. Adoptees in this study provided examples of how this lack of information impacts their lives and the life of their children.

\section{First Nation Adoption Legislation}

FNCFAs, First Nations, provincial governments and the federal government should keep working toward legislation in Canada that would contain provisions for First Nation adoption. The rationale for this recommendation has been spelled out clearly in this study - First Nation communities across Canada have jurisdiction over First Nation adoption. How this ensues however may vary by jurisdiction and a number of options may be explored depending on the customs and traditional community-based laws and protocols around adoption.

\section{Conclusion}

For the most part, the story of First Nation adoption remains mostly in the hearts and minds of adoptees themselves, and the body of literature is incomplete without these valuable stories. However, First Nation adoption is a sensitive subject that has presented several challenges to scholars. For example, there are legal issues related to privacy legislations that must be considered. Legislators view the privacy of all parties in the adoption triad as important. In fact, some adoptees do not want to speak about their experiences because it is too painful. However, scholars may overcome some of these barriers by working with local community agencies, such as the Yellowhead Tribal Services Agency in this study.

The best interests of First Nation children are part of a debate that stems from a colonial legacy. Alfred and Corntassel (2005) state that:

Contemporary Settlers follow the mandate provided them by their imperial forefathers' colonial legacy, not by attempting to eradicate the physical signs of Indigenous peoples as human bodies, but by trying to eradicate their existence as peoples through the erasure of the histories and geographies that provide the foundation for Indigenous cultural identities and sense of self (p.2).

Societal issues of racism and poverty with health-related outcomes are priorities that need to be addressed in First Nation communities, but issues related to First Nation children are not addressed by simply implementing 'culturally relevant' programs and services.

For natural parents and for adopted people, it is not forgetting your past and your history that allows you to move forward with your life. Rather, it is acknowledging the past and honoring its impact that makes the present more meaningful and allows you to look to the future with confidence (Robinson, 2000, p.57).

I reflect on my research question and the research results, now knowing that connectedness and health for First Nation adoptees are related in a significant way. There is a link between knowing who you are, where you come from and how you feel as a 
whole person. This connectedness has been explored and described through the voice of those who know. I trust that it may assist you in positions of power and decision-making that the responsibility to change someone's life is the Creator's work, not ours as mere human beings.

All my relations!

\section{Endnotes}

1. Some of the adoptees interviewed for this present study were involved with the Manitoba First Nation Repatriation Program. As such, some of the findings in this study replicate the findings from the Evaluation of the Southern Manitoba First Nation Repatriation Program.

2. Identity is a sub-category under the core category of loss.

\section{Bio}

Jeannine Carriere has been working in the field of Aboriginal child welfare for over twenty years. Jeannine has an MSW from UBC, a BSW from the University of Manitoba and currently completed a PHD in Human Ecology, Family Studies at the University of Alberta. Jeannine also teaches in the Faculty of Social Work, for the University of Victoria. In her PHD work, Jeannine examined the issue of First Nation adoption. Her research involved interviewing First Nation adoptees from across Canada and holding focus groups of First Nation Elders, and professionals in the area of adoption. This course of study has provided some valuable insights into the connection of identity to resilience for First Nation adoptees and other related health issues from a holistic perspective.

\section{References}

Alberta Children's Services. (1984). Statutes of Alberta - Child Welfare Act. Vol. Chapter C-8.1.

Alberta Children's Services. (1997). Policy directive in the adoption of First Nation children. Edmonton, AB.
Alberta Children's Services. (2004). Alberta Regulation 187/2004. Adoption Regulations.

Alfred,T., Corntassel, J. (2005). Being Indigenous: Resurgence against contemporary Colonialism. Preprint for Government and Opposition. Blackwell Publishing.

Anderson, K. (2000). A recognition of being: Reconstructing native womanhood. Toronto, ON: Second Story Press.

Bennett, M. and Cyr, J. (2001). Evaluation of the Southern Manitoba First Nation Repatriation Program. Winnipeg, MB: Southern First Nations CFS Directors of Manitoba.

Bennett, M. and Blackstock, C. (2002). A literature review and annotated bibliography focusing on aspects of Aboriginal child welfare in Canada. Winnipeg, MB: Centre of Excellence for Child Welfare.

Brendtro, L.K., Brokenleg, M., \& Bockern, S.V. (1990). Reclaiming youth at risk. Bloomington, IN: National Education Service.

Cajete, G. (2000). Native science natural laws of interdependence. Santa Fe. NM: Clear Light Publishers.

Child Welfare League of America. (2000). Adoption and ethics. Washington.

Coles, G. (2004). Ever after: Fathers and the impact of adoption. Australia: Clova Publications.

Creswell, J. (1998). Qualitative inquiry and research design. London: Sage. 


\section{First Peoples Child \& Family Review, Volume 3, Number 1, 2007}

De Aguayo, A. (1995). Background paper on customary adoption. RCAP Notes. Ottawa, ON: Royal Commission on Aboriginal Peoples Report.

Fanshel, D. (1972). Far From the Reservation: The Transracial Adoption of American Indian Children. NJ: Scarecrow Press.

Fournier, S., \& Crey, E. (1998). Stolen from our embrace. Vancouver, BC: Douglas \& McIntyre.

Government of Canada. (1996). Royal Commission Report on Aboriginal Peoples. Ottawa, ON: Royal Commission on Aboriginal Peoples.

Grotevant, H.D., Dunbar, N., Kohler, J.K., \& Esau, A.M.L. (2000). Adoptive identity: How contexts within and beyond the family shape developmental pathways. Family Relations, 49, 379-387.

Indian and Northern Affairs Canada. (2002). Basic departmental data. Retrieved from http.www.inac.gc.ca/pr/sts/index_e.html September 12th, 2004.

Kral, M.J. (2003). Unikaartuit: Meanings of well-being, sadness, suicide and change in two Inuit communities. Final report to the National Health Research and Development Programs. Ottawa, ON: Health Canada.

Lather, P. (1991). Getting smart, feminist research and pedagogy with/in the postmodern. New York: Routledge.

Lazarus, K.B. (1997). Adoption of Native Americans and First Nations children: Are the United States and Canada recognizing the best interests of children? Arizona Journal of International and Comparative
Law, 14(1), 255-284.

Locust, C. (2000). Split feathers. Adult American Indians who were placed in non-Indian families as children. Ontario Association of Children's Aid Society, 44(3), 11-16.

Menard, B. J. (1997). A birth father and adoption in the perinatal setting. Fundamentals of perinatal social work: A guide for clinical practice. Social Work Health Care, 24,(3-4), 153-63.

Mirwaldt, J. (2004). Permanency Planning. Trend Analysis and Recommendations. Report of the Western Provinces' Children's Advocates Working Group. Updated Sept. 2004. Presented by Canadian Council of Provincial and Child Youth Advocates at: Building Lifelong Connections: Permanency Options for Children and Families. New Brunswick.

National Aboriginal Health Organization. (2004). First Nations center. Ownership, control, access, and possession (OCAP) or self-determination applied to research. Journal of Aboriginal Health 1(1), 80-95.

National Indian Child Welfare Association. (1999). Multiethnic Placement Act and amendments: Potential impacts on Indian children. Retrieved May 14, 2002 from http//www.nicwa.com.html.

Ontario Child and Family Services Act. 2002. Revised Statutes of Ontario. chap. C11.sec. 213.

Olesen, V. (1994). Feminisms and models of qualitative research. In N.K. Denzin, \& Y.S. Lincoln (Eds.), Handbook of Qualitative Research (2nd ed.), 158174. Thousand Oaks, CA: Sage. 


\section{Promising practice for maintaining identities in First Nation adoption}

Province of Saskatchewan Court of Queen's Bench. (2004, December). Family Law Division 503. In The Matter of Child and Family Services Act, p.28.

Rechner, R. (2001). Children's advocate annual report. Edmonton, AB: Alberta Children's Services.

Robinson, E. (2000). Adoption and loss: The hidden grief. Australia: Clova Publications.

Rubin, H.J., \& Rubin, I.S. (1995). Qualitative Interviewing: The art of hearing data. Thousand Oaks, CA: Sage.

Rutman, D.,Strega, S., Callahan, M., Dominelli, L. (2001). Young Mothers in/from Care Project: Proceedings of April 3,2001 Forum on Policy and Practice. Child, Family and Community Research Program. School of Social Work. University of Victoria.

Samson Flood, R. (1995). Lost Bird of Wounded Knee, Spirit of the Lakota. New York: Scribner Publisher.

Sinclair, R. (2004). Aboriginal social work education in Canada: Decolonizing pedagogy for the seventh generation. First Peoples Child and Family Review, 1(1), 49.

Society of Special Needs Adoptive Parents. (2003). Adoption piece by piece: Lifelong issues. S. Graefe (Ed.) Vancouver, BC: Ben Simon Press.

Spears, S. (2003). Strong spirit, fractured identity: An Ojibway adoptee's journey to wholeness. In Anderson, K., Lawrence, B. (Eds.), Strong Women's Stories: Native vision and community survival. Toronto, ON: Sumach Press.
Teichrob, R. (1997). Flowers on my grave. Toronto, ON: Harper-Collins Publishers.

Trocme, N., Knoke, D., \& Blackstock, C. (2004). Pathways to the over representation of Aboriginal children in Canada's child welfare system. Social Services Review. December. 578-599.

Yeo, S.S. (2003). Bonding and attachment of Australian Aboriginal children. Journal of Child Abuse Review. Vol. 12: 292-304.

Yellowhead Tribal Services Agency. (2001). Report on Open-customary Adoption. Edmonton, AB: Yellowhead Tribal Services Agency. 